in amino-acid concentration enhanced aminoacid and glucose utilization for lipogenesis, with no increase of lipogenesis measured by glycerol incorporation for incubation times below $10 \mathrm{~h}$.

Insulin increased glycerol incorporation ( $+35 \%)$ into cellular lipids and consequently lipogenesis. Insulin increased more strongly amino-acid and glucose incorporation into cellular lipids, the glucose incorporation showed a synergistic effect between insulin and amino acids for up to $1.59 \mathrm{~g} / \mathrm{l}$ amino acid in the medium (increase in the presence of insulin was of 2 at $0.3 \mathrm{~g} / \mathrm{l}$ to 10.6 at 1.59 $\mathrm{g} / \mathrm{l})$. At concentrations above $1.59 \mathrm{~g} / \mathrm{l}$, the synergistic effect decreased (5-6); this is in accordance with the inhibitory effect of amino acids on insulin stimulation of amino-acid transport by hepatocytes in primary culture.

In contrast, insulin decreased lipid secretion measured by glycerol $(-35 \%)$ and glucose incorporation. This decreased glycerol incorporation was correlated with the medium amino-acid concentration. When the amino-acid concentration was lower than $1.19 \mathrm{~g} / \mathrm{l}$, insulin increased aminoacid incorporation, but it decreased amino-acid incorporation if the concentration exceeded this value. This effect accounts for the controversy over the insulin action on VLDL secretion.

\section{Substrate utilization by bovine and ovine adipose tissue explants cultured for 2-7 d: effects of insulin and/or dexame-}

thasone. Y Faulconnier, L Guillon, J Fléchet, Y Chilliard (INRA, Laboratoire SousNutrition des Ruminants, 63122 SaintGenès-Champanelle, France)

Effects of crystalline bovine insulin (Sigma, 2 $\mathrm{mU} / \mathrm{mL}$ ) and/or dexamethasone (Dex, Sigma, $100 \mathrm{nM}$ ) were studied on perirenal adipose tissue (AT) from non-lactating non-pregnant cows ( $n$ $=5)$ and ewes $(n=5)$ fed on a restricted diet which provided $20-22 \%$ of the energy maintenance requirement, EMR for 8-10 $d$ and then overfed ( $188 \%$ or $228 \%$ of the EMR, for cows or ewes) for 21 (cows) or 10 (ewes) d until slaughter. AT explants were cultured in sterile conditions for $2-7 \mathrm{~d}$. The amount of glucose removed from the culture medium was determined daily for $7 \mathrm{~d}$ using the glucose dehydrogenase method and acetate utilization for $\mathrm{d} 1-2,3-4$ and 5-6-7 using an enzymatic method. Culture medium contained $5.5 \mathrm{mM}$ glucose and $7.6 \mathrm{mM}$ acetate, and was changed daily. In basal conditions, glucose and acetate utilization was similar in bovine and ovine AT explants (table I). Acetate utilization on d 1-2 was 3 times greater than glucose utilization, but they were similar after $d 4$.

The addition of insulin tended to increase glucose utilization by bovine AT explants. However, the effect of insulin on $d 3-4$ and $d 5-7$ was greater in ovine $(112 \%$ increase) than in bovine AT $(+57 \%)$. The addition of Dex to the insulinsupplemented medium increased further $(P<$

Table I. Effects of insulin $(\mathrm{I}, 2 \mathrm{mU} / \mathrm{ml})$ and/or dexamethasone $(\mathrm{D}, 100 \mathrm{nM})$ on glucose and acetate utilization by bovine and ovine adipose tissue in culture ( $Y$ Faulconnier et al).

\begin{tabular}{|c|c|c|c|c|c|c|c|c|}
\hline & \multicolumn{4}{|c|}{ Days 1-2 } & \multicolumn{4}{|c|}{ Days 5-7 } \\
\hline & Control & 1 & $D$ & $I D$ & Control & 1 & $D$ & $I D$ \\
\hline \multicolumn{9}{|l|}{ Glucose 1} \\
\hline Bovine & $31^{\mathrm{ab}}$ & $49^{a}$ & $17^{b}$ & $39 a$ & 17 & 26 & 18 & 19 \\
\hline Ovine & $36^{b}$ & $51^{a}$ & $16^{c}$ & $50^{a}$ & $15^{\mathrm{c}}$ & $35^{b}$ & $9^{c}$ & $52^{a}$ \\
\hline \multicolumn{9}{|l|}{ Acetate 1} \\
\hline Bovine & $95^{b}$ & $117^{a b}$ & $47^{c}$ & $132^{\mathrm{a}}$ & $20^{b}$ & $55^{a}$ & $13^{b}$ & $70^{a}$ \\
\hline Ovine & $99^{a}$ & $103^{a}$ & $49 b$ & $114^{a}$ & $12^{\mathrm{bc}}$ & $29^{b}$ & $6^{c}$ & $65^{a}$ \\
\hline
\end{tabular}

\footnotetext{
1 Utilisation as $\mu \mathrm{mol} / 24 \mathrm{~h} / 10^{6}$ adipocytes. a,b,c means in the same row and for the same culture duration with different letters differ $(P<0.05)$. The adipocyte number of explants was calculated from the mean cell volume determined after tissue fixation in osmium tetroxide.
} 
$0.05)$ glucose utilization by ovine AT on $d 3-4$ $(+33 \%)$ and $d 5-7(+45 \%)$, but tended to decrease this utilization by bovine AT. The addition of Dex alone decreased glucose utilization by ovine $(-43 \%)$ and bovine $(-51 \%)$ AT explants during the first $4 \mathrm{~d}$ of culture.

The addition of insulin tended to increase acetate utilization by ovine and more markedly by bovine AT explants. The addition of Dex to the insulin-supplemented medium increased further $(P<0.05)$ acetate utilization by ovine AT on d 3-4 and d 5-7 (increases by 74 and 120\%, respectively), although it had no significant effect with bovine AT. The addition of Dex alone decreased (about 50\%, $P<0.05$ ) acetate utilization on $\mathrm{d} 1-2$ in the 2 species.

These results show large interactions between hormone and animal species effects on substrate utilization during 1 week's culture of ruminant AT.

\section{Nutritional regulation of insulin regu- lable glucose transporter in bovine muscle. JF Hocquette 1, F Bornes 1, B Graulet 1, D Dardevet 2, M Vermorel 1, Y Geay ${ }^{1}$, P Ferre ${ }^{3}\left({ }^{1}\right.$ INRA, Laboratoire Croissance et Métabolismes des Herbi- vores, UR Métabolismes Énergétique et Lipidique; 2 INRA, Laboratoire d'Étude du Métabolisme Azoté, 63122 Saint-Genès- Champanelle; ${ }^{3}$ INSERM U342, 82, ave- nue Denfert-Rochereau, 75014 Paris, France)}

Growing ruminants convert ingested proteins and energy to body tissues relatively inefficiently. For a better understanding of basic biological mechanisms that could improve nutrient utilization, the regulation of rate-limiting processes of muscle metabolism must be studied. Glucose transport across the plasma membrane is a rate-limiting step for glucose utilization. GLUT4 is the main isoform of glucose transporter in the muscle of monogastric mammals. Moreover, GLUT4 is the primary isoform responsible for acute insulin-stimulated glucose transport. The aim of this work was to characterize GLUT4 and to study its nutritional regulation in calves at the time of weaning. Weaning induces large nutritional changes which could alter regulation of glucose metabolism: bovine suckling is characterized by dietary supply of fat and carbohydrate (35-45 and $30-40 \%$ of energy intake, respectively). In contrast, short-chain fatty acids and ketone bodies are the main energy-yielding substrates after weaning $(60-70 \%$ of energy intake) because of food degradability and digestion by microbes in the reticulo-rumen.

The present experiment was conducted on 2 groups of 7 Montbéliard calves: 1 group of suckling calves and 1 group of weaned calves. Net energy intake from birth and age (170 d) and empty body weight $(194 \mathrm{~kg})$ at slaughter were identical for the 2 groups so that only the effect of energy-yielding substrate changes was studied.

Glucose transport rate was measured in vitro for 20 min using 2-deoxyglucose in muscle fiber strips of Rectus Abdominis (an oxido-glycolytic muscle), which were incubated at $37^{\circ} \mathrm{C}$ in the absence or presence of insulin $\left(10^{-6} \mathrm{M}\right)$ for basal or stimulated glucose transport rate measurements. Glucose transport rate was increased by weaning or insulin $(p<0.01)$. The acute stimulation of glucose transport by insulin suggested that GLUT4 was expressed in bovine muscle. Basal and insulin-stimulated glucose transport rates were higher in weaned calves than in suckling calves $(+31 \%$ and $+43 \%$ respectively; $p<$ $0.01)$. Stimulation of glucose transport by insulin was higher in weaned calves than in suckling calves $(+325 v s+201 \mathrm{nmol} \mathrm{DOG} / \mathrm{g}$ of wet tissue/20 min; $p<0.01$ ).

It has been previously reported that the change in glucose transport rate and insulin sensitivity in rats at the time of weaning were associated with an increase in the amount of GLUT4 in muscle. To test this hypothesis, GLUT4 protein was quantified by immunoblotting using a polyclonal antibody raised against a 12 amino acid peptide of the carboxy terminus of rat GLUT4 sequence. Studies were performed after muscle homogenization and protein solubilization by Triton $X-100$ on samples taken from 7 muscles. A specific band of $42 \mathrm{kD}$ corresponding to GLUT4 was observed. However, no difference in the amount of GLUT4 transporters was detected between suckling calves and weaned calves in the 7 studied muscles. This suggested another level of regulation of GLUT4 activity, for instance, a modification of the intrinsic activity of the protein or a change in the efficiency of GLUT4 translocation following insulin-stimulation.

Whatever the nature of the feed (milk or forage), the concentration of GLUT4 was much 